\section{AURORA AND MAGNETIC DISTURBANCES OF AUGUST 27, I9I6.}

WITH reference to the aurora reported by $\mathrm{Mr}$. W. F. Denning at Bristol on August 27, between 2 and 4 a.m. G.M.T. (Nature, August $3 \mathrm{I}$, p. $55 \mathrm{I})$, the Director of the Meteorological Office notes a report received from Mr. J. Ernest Grubb, observer at Seskin, near Carrick-on-Suir, Co. Waterford, Ireland, that aurora was visible there on the night of August 26 between 10.5 and 10.40 p.m. G.M.T. The greatest display noted by $\mathrm{Mr}$. Grubb occurred about I0.25 p.m., when streamers from N.W. to N.N.E. stretched to within $20^{\circ}$ or $30^{\circ}$ of the zenith. The light rvas sufficiently brilliant to illuminate the interior of a room facing W.N.W.

At Eskdalemuir, Dumfriesshire, in spite of a cloudy sky, auroral glow in the N.W. was reported by the observer at 9 p.m. on August 26 and I a.m. on August 27. The magnets at Eskdalemuir and Richmond (Kew Observatory) were considerably disturbed, especially at the former station. The full amplitude of the disturbance there in the north and vertical components cannot be assigned, owing to the limit of registration being passed, but the range in each element considerably exceeded $400 \gamma$ ( $\gamma \equiv \mathrm{I} \times \mathrm{IO}^{-*}$ C.G.S.), and in the west component it was fully $300 \gamma$. At Kew the ranges of the horizontal force and vertical force were approximately $250 \gamma$ and $200 \gamma$ respectively. Declination at Kew had a range of $27^{\prime}$, the most rapid movements occurring early on August 27 ; the extreme easterly position was reached at about $2.5 \mathrm{a} . \mathrm{m}$., and the extreme westerly at about 2.35 a.m.

A notable feature, especially at Eskdalemuir, was the "sudden commencement," introducing the storm at about 7.45 p.m. on August 26 . Its oscillatory character was particularly well shown in the north component, a very rapid fall of I $\gamma$ preceding a rapid rise of roo $\gamma$. After this commencement the horizontal component at Eskdalemuir and Richmond (Kew Observatory) remained above its normal value until about io p.m., when it fell below normal and remained so, while oscillating considerably, during the rest of the disturbance. The depression in the horizontal component at Kew Observatory at 6 a.m. on August 27, when the storm was nearly over, exceeded Ioo $\gamma$. An interesting feature in the vertical force curves at Eskdalemuir towards the end of the storm after 6 a.m. on August 27 is a series of oscillations of short period, averaging about 4.6 minutes, which recall a similar phenomenon observed there in the storm of November $5-6$, 1915 .

The display of Aurora Borealis on August 26-27 was observed by Dr. John Satterly in Canada. Writing from Jackson's Point, Lake Simcoe, Ontario, Dr. Satterly says that on August 26 the whole northern sky from horizon to zenith was illuminated for several hours. On the horizon there was a strong yellowish glow with streamers radiating upwards Arcs of light encircled the zenith, and flickering bands and patches of colour were seen in middle altitudes. The smallest newspaper headlines could be read at in p.m. On August 28 the northern lights were feeble, but at ro.30 p.m. (Eastern time) an immense riband of light, practically a complete semicircle, spread across the sky. It extended from the east and rose a few degrees south of Jupiter, threaded Pegasus diagonally, cut Cygnus, passed through Lyra to the north of Vega, and dipped down through Hercules to the west. Stars in their apparent rotation passed across it, so that the band was fixed relatively to the earth. The arc inter-

NO. 2447, VOL. 98$]$ sected the Milky Way at about $60^{\circ}$ or $70^{\circ}$, very nearly at the zenith; it was much brighter and narrower and more definite than the Milky Way. No portion of the arc appeared in the northern sky. At II. 15 p.m. the western half faded away gradually, and at II. 30 p.m. the eastern half vanished.

\section{THE SAKURA-JIMA ERUPTION OF JANUARY, I9I4.}

PROF. OMORI has recently published a second valuable memoir on the eruption of Sakura-jima, which occurred on January I2, 19 I $^{4} .^{1}$ The volcano lies in Kagoshima Bay, in South Japan, a few miles to the east of the city of Kagoshima. Until the last eruption Sakura-jima was an island. It is now connected by a lava-stream with the east side of the bay. The part of the bay lying to the north of Sakura-jima ranges in depth from 70 to 107 fathoms, and is apparently of the same origin as the deep lakes which are found behind the sea-coast volcanoes of Usu-san and Tarumai-san.

Displacements of the Ground.-Soon after the eruption it was noticed that the sea-level had undergone an elevation relatively to the adjoining coast. At high tides the low districts at the south end of Kagoshima were flooded. Along the north-west and north coasts of Kagoshima Bay the rise of the water was still greater, embankments and stone walls being damaged and extensive rice-fields devastated. The amount of the sea-level elevation was nearly a metre at Kagoshima and two metres or more in Sakura-jima. The apparent sealevel elevation was greatest at the end of 1914 , after which it began to decrease.

Prof. Omori attributes this change to the depression of the ground in the neighbourhood of Sakura-jima in consequence of the great eruption. This depression was revealed with greater precision by a renewal of the Military Survey levelling of the district and of the levelling along the railway lines near Kagoshima Bay. Prof. Omori has represented the results on a map on which are drawn the curves of $50,100,300$, and $500 \mathrm{~mm}$. depression. The curves of 300 and $500 \mathrm{~mm}$. run close to the coast of the northern portion of Kagoshima Bay. The axes of these curves, which are directed north and west respectively, intersect in a point lying off the north coast of Sakura-jima, and Prof. Omori regards this point as indicating the centre of the area of greatest depression of the ground. The total depression-volume within the Ioo-mm. curve is I.35 c. $\mathrm{km}$. The aggregate volume of lava flows and pumice and ash ejection during the recent explosion is about $2 \cdot 2$ c. $\mathrm{km}$.

It is important to notice that the point of maximum depression, which probably coincides with the principal centre of the lava reservoir, lies, not under Sakura-jima, but in the region between it and the active volcano of Kirishima.

The triangulation surveys of 1898 and I9I4 also reveal considerable displacements, both horizontal and vertical, in Sakura-jima, while the coast of the island is everywhere depressed. Three points in the interior have been raised 0.14 and about 9.7 and 10.4 metres. The horizontal displacements in the north-west of the island vary from $2 \cdot 04$ to 3.62 metres towards the south, and in the west and north by amounts from I.08 to 4.52 metres towards the north and north-east. The north and south portions of Sakura-jima have thus been displaced outwards in contrary directions.

"The Sakura-jima Fruptions and Earthnuakes." II. "Bull. Imp Earthq. Inv. Com., vol. viii., 1916, pp. 35-179. The first memoir was noticed in NA TUR E, vol. xciv., p. 289 ; se also vol. xcii., pp. 7 r6-r7. 